\title{
A CDA of Thai and American Music Radio Programs in Terms of the Influence of the Language of American Culture on the Language of Thai Culture
}

\author{
Sumanawika Unchit \\ Graduate School of English, Assumption University of Thailand \\ sumanawika@gmail.com
}

\begin{abstract}
This study is concerned with the main linguistic differences and similarities between the Thai and American DJs' conversations on the radio and the influence of American culture on Thai culture (in terms of language) as seen in those conversations. There were three radio stations chosen for comparison: SEED 97.5 FM, MET 107 FM, and New York PLJ 95.5 FM. DJS' conversations are analysed from the perspective of code switching, language appraisal, ecology of language, speech genres, and sociolinguistics. The result show both differences and similarities. Thai and American radio feature different points of view and cultural beliefs. However, the three data samples data also show similarities related to the music content.
\end{abstract}

Keywords: CDA, radio program, American culture, Thai culture 


\section{INTRODUCTION}

According to the Thai media historian, Siritip Khansuwan (Khansuwan, 1996), the beginnings of radio broadcasting in Thailand can be traced back to 1927 when The Ministry of Telecommunication, initiated experiments on radio communication. The actual date of the first broadcast was 25 February 1930. It was the Thai Coronation Day. The radio broadcast King Rama VII's speech to his subjects all across the country. After that, the radio was controlled and run by the government. Originally, most of the radio content was concerned with education, economy, and entertainment. When the government could no longer cover the expenses of running the station, they allowed the business sector to advertise its products on air and by doing so they generated revenue with the air time. The aired content was strictly controlled. Advertisements were only allowed to mention what the product was, what it was for, and which company made it. All advertisements followed the same structure with no additional details, otherwise they would not be allowed to air.

Things started to change after World War II when the radio began to broadcast more programs and music. At that time, the government allowed other units to own and operate radio stations but they continued to control the appropriateness of their content. When the government saw how quickly the radio business grew, they established the Thai Television Company which later became MCOT. In order to control the content on air more effectively, the government set up the Board of Radio Broadcasting in 1975.

Today, most of the better known Thai radio stations still remain under governmental control but business units can rent or buy air time for their advertising and promotion. Information available on MCOT's website reveals that the Mass Communication Organization of Thailand was changed to MCOT Public Company Limited. It runs two main businesses that are operated by the company itself Modern Nine television and radio broadcasting. In terms of radio broadcasting, the company produces the content, does the marketing, and manages the operation by itself. MCOT radio stations MCOT are available both domestically and internationally via radio waves, Internet, and smart phone application. Social media like Youtube, Facebook and Instagram also facilitate interaction between radio audiences and DJs. MCOT operates several radio stations, each with their own audience:

- Mahanakorn Family 95 FM presents Thai local music which is called luk thung.

- Brainwave 96.5 FM offers its audience information about economy, politics, and 24 hours news.

- Seed 97.5 FM presents modern mainstream music from all record labels with Thai and English songs, as well as hits from other Asian countries like South Korea.

- Active 99 FM broadcasts stories about health, sports, recreation and travel.

- News Network 100 FM is a news hub for other radio networks. (MCOT Company's Business, 2015) 
Although Thai radio was originally meant to be used by the military and government for political causes, today its purpose is mainly commercial. Technology and business play significant roles to keep the radio business alive. Radio stations compete with each other to attract mass audiences because the bigger the audience, the more revenue from advertising they can generate. They woo their audiences with popular songs, fresh lifestyle content, or interesting stories. MET 107 , one of the stations examined in this paper, is frequently considered one of the more popular Thai radio stations. It targets an audience that is defined by its active lifestyle with a content that is a lively mix of mainstream music and trendy lifestyle updates from all over the world. MET 107 uses traditional radio broadcasting methods and it is also available as an online radio on computers, and through smart phone and tablet applications. Interactions with radio DJs are extended to the social media platforms, like Facebook and Instagram. Thanks to its strong relationship with a versatile audience, the radio is seen as attractive to sponsors (J. Jeerapat, personal communication, 20 December, 2014).

One characteristic feature of MET 107 is the fact that some of its DJs speak English throughout the entire program. SEED 97.5's DJs also occasionally introduce English vocabulary, even though they speak in Thai. As international music and the use of English can be said to shape Thai radio discourse, this may have an impact on Thai culture. It may change the ways Thais understand and interpret information based on the format of its presentation, the types of information presented, and its content. Furthermore, whenever language is used for communication, it carries with it a capability of producing, maintaining and changing the social relations of power (Fairclough, 1989: 6). Therefore, the aim of this article is to analyze the cultural impact of the English language and English language media on Thai culture, and to highlight a small spectrum of language and its power to change social conventions.

In order to understand what is happening with the Thai media now, it is necessary to understand how Thai media are impacted by English language media, particularly in the area of the cultural content and communicating Thai culture to Thai audiences. As soon as other cultures in music and fashion are included into the dialogue, we can expect changes in various other aspects of cultural awareness. If the language of Thai popular culture is shifting in the significant domain of musical radio broadcasting, and if such a shift takes place, at least in a part, under the influence of American pop culture models, then it is important to document where in the language (English used in Thailand and Thai) this shift is occurring. If such a shift is clearly understood, then the decisions about how to use English in the Thai media will be more informed in terms of the linguistic impact of other cultures on Thai culture.

The focus of this study is the content of Thai and Western radio stations. ${ }^{1}$ Programs from three radio stations, namely MET 107 FM, SEED 97.5 FM, and PLJ

\footnotetext{
${ }^{1}$ The study focuses on the language used during conversations on air and reactions of the audience while they are listening to the program. The interactions in social media, such as Facebook, Instagram, and Twitter, or through other channels of communication are excluded because this study focuses only on verbal conversation.
} 
New York 95.5 FM will be used as case studies. MET 107 is a Thai music radio station with international content which is under the administration of MCOT. It has a clear target audience which consists of the younger generation, ranging from teenagers up to 35 year-olds. It broadcasts mostly (although not only) newlyreleased songs and gives advice on modern international lifestyle. The program is presented in both Thai and English. To attract an English speaking audience, or those who want to learn English, the station also offers news from international leading news agencies: BBC, VOA, Radio Australia, and OANA. SEED 97.5 is also under the administration of MCOT, yet its music and target audience are different. The station promotes Thai music, both mainstream and non-mainstream, whereas international music is played only sometimes. The American radio station in this study, PLJ New York 95.5 FM is under the control of Cumulus media - the second largest radio operator in the US. The station plays mainly popular music with a wide range of DJs and programs. This station was used as a comparison because its characteristics are similar to SEED 97.5 and MET 107: it is one of the leading national radio stations, it is based in a major city, and has a similar content to SEED 97.5 and MET 107 in Thailand.

\section{THAI RADIO, LANGUAGE AND CULTURE}

When it comes to social change, there are many factors that contribute to the way media influence society. Radio can not only contribute to changes in a particular group of people, but it can also have a large-scale influence on a national scale. In Thailand, MET 107, a station that offers exclusively non-Thai music and whose DJs frequently switch between Thai and English on air, shapes the way Thais listen to music and the way they use language to talk about music. When the DJs talk about the songs and music videos, the audience is exposed to a specific way of expressing concepts and ideas about pop music and pop culture and will likely adapt some of these expressions for future use. This means that the MET 107's audience learns English by listening to the conversations of the DJs, as well as to the songs played by the station. The content that the DJs discuss, e.g. the meaning of the lyrics, can have an impact on the listeners. This method of presentation can have an impact on the way Thai audience enjoys music.

English words frequently find their way into DJs' conversation on Thai radio. For example, a DJ from SEED 97.5 says, "A new single from Tattoo Colour is waiting for you." "Single" is an English word but the entire conversation in the program is in Thai. Similarly on MET 107: "It is the concept for next year for MET 107." This is known as code-switching - "a form of linguistic communication where the speaker makes use of elements from two or more different codes" (Foley, 2013: 84). Foley suggests there are five most common reasons behind codeswitching: 1) fluency or memory problems in the second language, 2) switching from informal to formal situations 3) exerting control, 4) aligning speakers with others in specific situations or 5) announcing specific identities, creating certain meanings, and facilitating interpersonal relationships (Foley, 2013: 84). 
It is possible that Thai radio DJs resort to code switching to announce specific identities. MET 107 DJ uses code switching to announce that he is a part of English-environment discourse while the DJ from SEED 97.5 switches the code to facilitate interpersonal relationships. The word "single" as referring to music is now widely used instead of the original Thai word for a "single." This may well be because "single" is a shorter word compared to its Thai equivalent.

Foley argues that "profound differences between languages must have consequences that go far beyond mere grammatical organization and must be related to profound divergences in modes of thought" (2013: 30). He reiterates after Kramsch that "words [...] reflect their authors' attitudes and beliefs, their point of view that are also those of others. In both cases, language expresses cultural reality" (Foley, 2013: 17). Since languages are influenced by cultures and, at the same time, cultures are shaped by their languages, when English is adopted by the Thai radio DJs it carries with it a number of cultural connotations. This may be of further consequence in Thailand if this exposure to English affects the ways Thais understand and interpret information, the types of information presented and the content of Thai culture. When MET 107's DJ talks about the song Champagne Life by the artist $\mathrm{Ne}$ Yo, he explains that the song is about a successful lifestyle and that "champagne" signifies success. This information may be new to the Thais, since the traditional symbol of success in Thailand is the parade - a triumphant march around the area where the successful person is from to celebrate his/her success. Similarly, when SEED 97.5's DJs joke about the law of Karma they refer to a specific Buddhist belief that may be misunderstood by non-Buddhism listeners. Buddhism is believed to be the dominant religion in Thailand and an important part of Thai cultural identity. Thus, to understand the message completely one needs to understand culture as well as the language.

Such shifts in language use and accompanying them expansion or change or cultural contexts may be interpreted as counteracting the officially stated aims of MCOT to present Thai arts and culture, or to accommodate international English language content in such a way that it promotes Thai culture. In spite of being the medium of modernity, Thai radio, like any other mass medium, is predictably influenced by powerful institutions. In the Thai context these are the nation, religion, and the king. Thai radio stations play the national anthem twice a day, they broadcast live transmissions from royal and religious ceremonies, and the government and the army continue to play a significant role in managing the stations. Radio has been a crucial tool for communication in Thailand for decades. It has become a technologically advanced tool to transfer cultural values. However, institutions, laws, and regulations are not the only factors that give radio its shape. Once it is obvious how language and culture affect one another, the language being used on radio reaches a critical point of importance and it should be considered critically to ensure it fits with the targeted community. Thus, personalities and presentations of each radio station can be different or similar depending on the context. 


\section{RESEARCH METHOD}

The study offers a comparison of Thai and American radio conversations. Conversation in this research means the talk between the DJs, as well as the DJs addressing the participating audience on the phone, or the silent audience listening to the program. The data was collected from three radio programs: SEED radio from SEED 97.5 FM, MET Music and Lyrics from MET 107 FM, and John Fox from New York PLJ 95.5 FM. SEED 97.5 FM is a Thai radio station that plays Thai mainstream music. The station is situated in Bangkok. MET Music and Lyrics is a program from MET 107 FM that plays international music with a mix of Thai and English speaking DJs. The station is also situated in Bangkok. John Fox is a program from New York PLJ 95.5 FM. This radio station is known for playing American music in New York, USA.

The study set out to find the differences and similarities between Thai and American radio conversations, and to find the significance of these differences and similarities. In order to do so, three sets of data samples data were recorded on the same date and time (according to the local time) on Monday 29th December 2014, from 5 to $6 \mathrm{pm}$. The data was transcribed in English and whenever necessary the Thai text was translated into English with the words originally used in English printed in bold. The people whose voices could be heard in the recordings were:

- Gunyootapong Nopakun (DJ Barge from SEED)

- Sarut Nawapraditkul (DJ Mill from SEED)

- Supawat Peeranon (DJ Champ from Met Music and Lyrics)

- Ding (a participating audience from Met Music and Lyrics)

- Mike Allen (a DJ from John Fox)

- Jacquelyn Carl (a traffic reporter from Joh Fox)

\section{FINDINGS}

\subsection{Radio Conversation and Code Switching}

Differences and similarities were found in the conversations related to code switching, language appraisal, ecology of language, and speech genres. The result revealed that code switching and fused lect was used in both MET 107 and SEED 97.5 sample data. PLJ 95.5 FM radio conversation was not included in this comparison since the program was in English.

Table 1. Code switching and fused lect in SEED 97.5 and MET 107 sample data.

\begin{tabular}{|l|l|}
\hline \multicolumn{1}{|c|}{ SEED 97.5 } & \multicolumn{1}{c|}{ MET 107 } \\
\hline DJ & DJ \\
\hline party & album \\
\hline single & featuring \\
\hline friend with benefit & MET 107 for life and music \\
\hline SEED session & concept \\
\hline exclusive & IG \\
\hline exclusive SEED & MET is everywhere \\
\hline & create \\
\hline
\end{tabular}




\begin{tabular}{|l|l|}
\hline & hashtag \\
\hline & Champagne Life \\
\hline & got a way to go \\
\hline & but it is worth the wait \\
\hline & MET hit hunter \\
\hline & hit \\
\hline & sponsor \\
\hline
\end{tabular}

MET 107 data showed more use of code switching than SEED 97.5, mostly because the content of the show made the DJ use more English. Besides, the DJ himself chose to switch the code (insertation) because he wanted to identify himself with the international music community or at least with the English-competent community.

\subsection{Radio Conversation and Language Appraisal}

Language appraisal is a way to observe how language is used by distinguishing different positions of the speakers. Martin enumerated three positions of speaking: attitudinal positioning, dialogistic positioning, and contextual positioning. Attitudinal positioning takes place when the speaker shows his personal ideas or expression, while dialogistic positioning happens when the speaker assumes that he has an audience. We speak of contextual positioning when the speaker refers to other sources of information rather than claiming that he/she expresses a personal opinion (Martin, 2002).

Regarding language appraisal, all three sets of data differed. SEED 97.5 had no outstanding position of the speakers. The DJs mostly talked about hard facts like New Year, song titles, artists' names, etc. MET 107s DJ conveyed more of attitudinal positioning because of the content. In his show, he was supposed to translate the lyrics from English into Thai so he had to choose idioms or vocabulary from the song to explain them to his listeners. All this was done during the show without any interruption from the audience. Thus, it can be said that the DJ expressed mostly his personal opinion. Even though it is possible that the show could have been scripted, there were words which identified the attitudinal positioning of the DJ, as it can be seen in Table 2.

PLJ 95.5 sample data showed different results. It featured contextual positioning as its outstanding position. When talking, the DJ referred to the news and shows in the US, he even played a voice recording of a Hollywood actor (Tom Hanks). This was obviously contextual positioning, as shown in Table 2. So was the traffic report.

Table 2. Conversation positioning of SEED 97.5, MET 107, and PLJ 95.5 sample data.

\begin{tabular}{|l|l|l|}
\hline $\begin{array}{l}\text { Sample data } \\
\text { from }\end{array}$ & $\begin{array}{l}\text { Outstanding } \\
\text { positioning }\end{array}$ & Word of defining position \\
\hline SEED 97.5 & None & \\
\hline MET 107 & Attitudinal positioning & interesting \\
\hline
\end{tabular}




\begin{tabular}{|l|l|l|}
\hline & & positive \\
\hline & & self-motivated \\
\hline & & my favorite \\
\hline & & similar to \\
\hline & Contextual positioning & she decided to \\
\hline & & by Walgreens \\
\hline & & they called \\
\hline & & he said \\
\hline & & a voice record of Tom Hanks \\
\hline
\end{tabular}

The reason behind the contextual positioning of PLJ 95.5 can be the fact that its traffic report had to cover a large area of New York very quickly. To do so, they had to refer to the source of information. Similarly, at the beginning of the show, the DJ talked about the news and he had to mention the source or quote a third person, so that his audience would understand that the news was not based on his opinion alone. In other words, the DJ and his traffic reporter used the quotes from other sources to project the attitude from themselves. Projecting, however, was not the only way the DJ used contextual positioning. At the beginning of the show the DJ said it was a "somber Christmas." Then he referred to the news and quoted a lady in the news to support his idea of somber Christmas.

\subsection{Radio Conversation and Ecology of Language}

Ecology of language is the idea that language is an ecosystem related to other ecosystems (Conlon, 2012), e.g. the English language in the Thai ecosystem or the Thai language in the international music ecosystem. This can help to explain how language and society relate to and affect each other. Differences, as well as similarities were found when analysing the data with the idea of ecology of language. SEED 97.5 and MET 107 data were similar in the main language used because both of them were in the Thai ecosystem. The DJs from both stations were forced to speak Thai since the official language of the radio station is Thai and most of its listeners are Thai. Likewise, PLJ 95.5's DJ and his traffic reporter were in the American ecosystem so the language they used was English. Even though the data differed with regard to the main languages, the way the DJs talked about music was similar. Artists' names, some song titles, or even their sponsors were mentioned from time to time. This was because they all were in the radio ecosystem and especially because these were commercial radio stations 


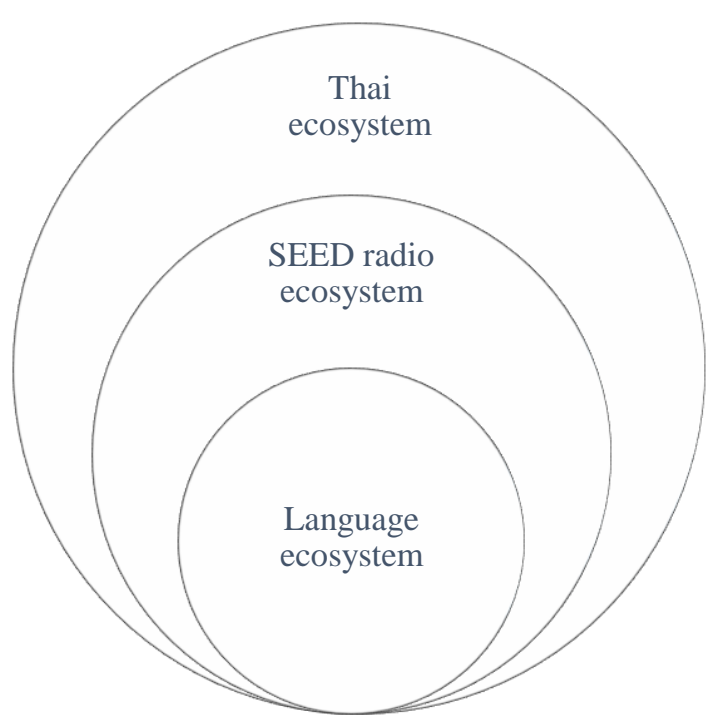

Figure 1. SEED ecology system

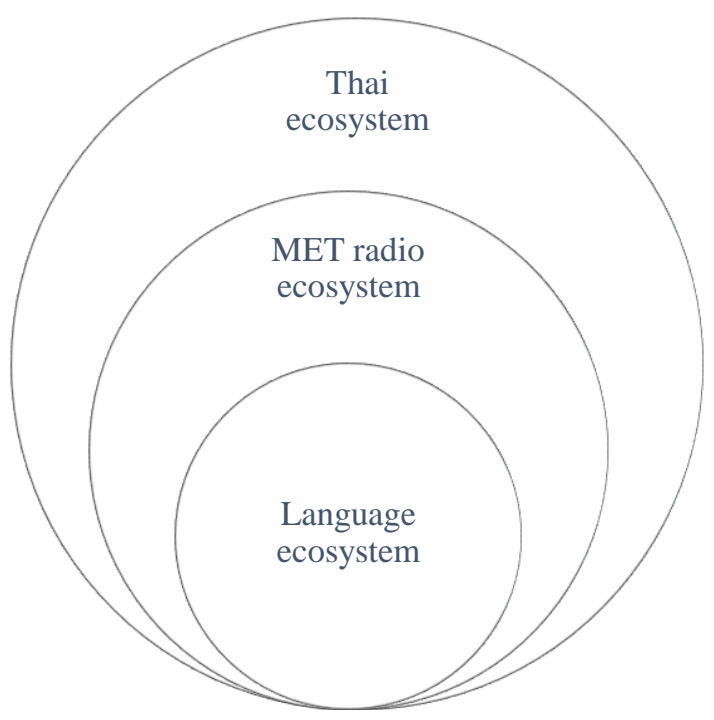

Figure 2. MET ecology system 


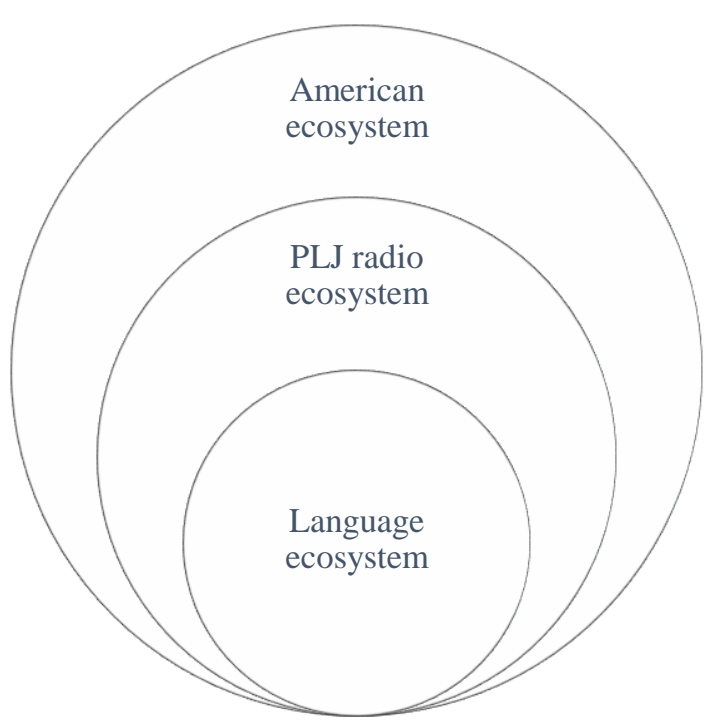

Figure 3. PLJ ecology system

The figures above show the differences and similarities among the three sets of data. PLJ 95.5's DJs and the traffic reporter constantly mentioned the sponsors of their shows, similarly to the DJ from MET 107 who said "thank you to Bridgestone for this period of the show." The traffic reporter from PLJ 95.5 also mentioned that Walgreens brought her the traffic report and talked about the benefits of products from Walgreens. All the DJs thanked their sponsors, as well as promoted and advertised their sponsors' products on air. Apart from the sponsors, all the DJs also mentioned song titles and artists' names. These similarities resulted from being a part of the radio ecosystem, especially the commercial radio ecosystem.

Differences were also found in the aspect of ecology of language. The most explicit ecosystem as seen in the figures is the main languages which were used in the show. Thai ecosystem made the Thai DJs speak Thai as the main language. Even though there was a mix of nationalities in the audiences in reality, the main target audience was Thai. Personalities of the show also differentiated them, as well as the topics and stories which were mentioned.

\subsection{Radio Conversation and the Problem of Speech Genres}

Bakhtin claims that no utterance is similar to one another because there are four components that make speech different from one instance to another: content, linguistic style, compositional structure and the sphere of communication (Bakhtin, 1986: 60). This idea relies much on the speaker as an individual. It helps to see how different radio conversations can be. All the three sets of data from SEED 97.5, MET 107 and PLJ 95.5 have different components that make them different. The linguistic style, with its lexical, grammatical and phraseological resources can help to see how different they are. Different DJs have different ways to put phrases together. They make different choices of vocabulary and they speak different languages. Consequently, every utterance they make is unique. The four components of speech genres are socially shaped. In other words, they are shaped by the relevant 
sphere of communication. Different cultures and languages result in different speech genres.

When the theory of speech genres was considered during the analysis, none of the speech samples (radio conversation) proved to be the same. Content (thematic), linguistic style, compositional structure, and the sphere of communication were the four factors analysed. For instance, the content of PLJ 95.5 is different from SEED 97.5 and MET 107 in that the DJ talked about Christmas during the show while none of the Thai DJs talked about such an event. The same can be said for the content of MET 107 because the show was supposed to educate the audience as well as entertain it.

The difference can also be seen in the aspect of linguistic style - lexical and grammatical resources. It is obvious that the American DJ and Thai DJs differ in this aspect. MET 107's DJ once said one English word during his show - "create" when he was supposed to say "creative". This is to show that each person has different lexical resources and it affects the way they speak. The DJ spoke two languages, Thai and English, and it is likely that he had mixed up the Thai grammar with the English vocabulary. The same example can also explain the difference in grammatical resources. MET 107's DJ spoke English differently or used English vocabulary differently from PLJ 95.5's DJ because he mainly relied on Thai grammatical resources rather than English. SEED 97.5's DJs also used an idiom "friend with benefit" during the talk. They did not use it for its meaning but to introduce the song since this idiom is the song title. Thus, this example can show how non-native speakers use English idioms: that is the DJs did not explain or mention the actual meaning of the phrase but only talked about it as the song title. Consequently, Thai audiences may not understand this idiom correctly, or they may understand it like the meaning of the song.

Besides, the sphere of communication made the DJs express themselves differently. The sphere of communication for MET 107 was international music for Thais. The DJ had to educate his listeners along with entertaining them with international music and related content. SEED 97.5's DJs had nothing to do with educating their listeners about English idioms and vocabulary since they provided Thai songs for Thai audience in Thai. There was not much to explain during the talk apart from mentioning the titles of songs. The PLJ 95.5's DJ also had different topics to talk about because he was in the American sphere of communication. Christmas time, American show, New York traffic report, etc. were all in the American sphere of communication.

\subsection{Dominant Cultures versus the Power of Media}

According to Gumperz (1982), the study of communication has pragmatic conditions which are culturally variable. These variations account for different cultural assumptions, ways of structuring argument, and different ways of speaking (Gumperz, 1982: 12). Therefore it can be claimed that culture plays a significant role in speech communication. Dominant cultures made each of the three data samples different in their own ways. There was more code switching in MET 107 sample data than in SEED 97.5 because its DJ had to present himself and his show as a part 
of the international music community. Yet the communication would be successful only when the DJ spoke Thai because his main target audience was Thai. It was the same for PLJ 95.5's DJ and his traffic reporter. American culture made them talk about Christmas. In this way dominant cultures had an impact on the data.

In terms of the ecology of language, American ecosystem had an influence on the content of PLJ 95.5 sample data. The sample data was recorded from 5 to 6 $\mathrm{pm}$ and that was the time for most of the people to leave work. Updates about traffic were one important or at least interesting piece of news to listen to. In contrast, MET 107 's DJ had to explain more about the meaning of the songs, for instance when he translated the lyrics of the song "Masterpiece" by Jessie J and explained its perspective on life, which would be seen as not immediately clear to the Thai way of thinking.

No speech was like another and the influence of dominant cultures was clearly visible. Even though speech genres seem to be dependent more on the speakers (DJs), the sphere of communication affects how the DJs talk as well. For instance, no matter how proficient the MET DJ was in English (based on how he explained the idioms, vocabulary, and lyrics), he still mainly had to speak Thai to his listeners because Thai culture and language were the sphere of communication. The thematic content of each sample data also reflected how dominant cultures influenced the conversation. SEED 97.5's DJs talked about the law of karma reflecting the fact that Thai culture is strongly influenced by Buddhism. Similarly, PLJ 95.5's DJ talked about Christmas. This shows that there was also a religious influence on the content of this data.

At the same time, we cannot ignore the power of the media. Behind a text circulating in the community has always a hidden agenda of the social structure (Fairclough, 1995; Fairclough, 2005; Fauzan, 2013). To illustrate, there was one piece of American music in SEED 97.5 sample data. SEED 97.5 claims to be a Thai radio station with Thai-speaking DJs that plays Thai music. Yet American music was found in the sample data. Today the media are interconnected and audiences are exposed to more than one kind of medium. The song in question was "Thousand Years" by Christina Perri that featured on a soundtrack from the movie Twilight. This Hollywood movie was also shown in Thai theatres. The soundtrack was introduced through the movie, but also on the radio and in other media. This could be the reason why the song was found on a predominantly Thai radio station. On MET 107 all the songs were in English. Additionally, the program introduced an American way of thinking to its Thai audiences although the language the DJ spoke was Thai. This likely introduced a new way of perceiving the world to Thai listeners.

\section{CONCLUSION}

Language and culture are changeable as well as interchangeable. American cultural influence on the Thai radio seems to be obvious. Language, culture, and society are continuously influencing each other. Therefore, the producers of Thai media have to consider how they want to develop their content in the future and thereby influence the direction of Thai media and culture. Should they follow 
American or other cultural influence, stay as conservative as they can, or eventually adopt the new culture as well as maintain the old one? Not only can the producers of the media benefit from the insights provided by this research. Also the consumers of the media themselves can benefit. The consumers can be more aware of new cultures and perspectives as well as how they might be influenced by the content they consume.

Media influence can contribute to many changes, although those changes are not explicit or sudden. The power of the media does bring the changes to Thai society and eventually has an impact on Thai language. MET 107 data revealed that most of the international music that was offered during the air time was American music. Occasionally, DJs talk about the making of music videos of the songs that are on air, or the listeners themselves search for some songs again on YouTube, or other media platforms. Words, fashion, etc. are learned and gradually adopted. When the DJ explains the meaning of the lyrics he does not only convey the literal meaning but also the perspective of the artists. The examples that were mentioned in the study were the songs "Champagne Life" by Ne-Yo and "Masterpiece" by Jessie J. The explanation of these two songs by the DJ can make audiences understand the perspective of western people, as well as adapt such attitudes in their lives. Such perspectives started to be adopted in Thai society already. There are champagne toasts in Thai wedding celebrations. This can prove that the western attitude to celebrating success has already been adopted and implemented in Thai culture and has already gone beyond language.

When cultures merge, the change affects their language but also other factors. The Thai language as spoken by Thai DJs was affected by American, with most visible examples being the instances of code switching There were also occasional examples of language misuse when speaking in English, although this did not hinder communication because the rest of the sentence was in Thai. For instance, SEED 97.5's DJ said "exclusive" instead of "exclusively," confusing the adjective with the adverb. Similarly, MET 107's DJ said "create" instead of "creative." The meaning of the sentences was conveyed because these English words were mixed in between other Thai words. But these two examples also illustrate that the Thais try to use English yet they rely on their mother-tongue's grammar.

Although Thai culture is influenced by American culture in terms of language, it still maintains its own characteristics. There are advantages and disadvantages of cultural flow (in this case, American cultural flow to Thai culture). The first advantage is that people from different cultures can communicate better since cultures are blended and explained through the media. Once people have a better understanding of one another's cultures, the barrier of cultural difference is lower. Besides, countries can do business better together and communication breaks down less often since languages and cultures are adjusted to fit one another. In contrast, embracing a foreign culture and language can also be disadvantageous to the original one. Code switching affects not only radio conversations but also daily business communication. People who work in the office use more English for email communication, even among the Thais. This can contribute to the disappearance of the local language. This is already happening with the Thai language and its dialects. 
For instance, Isan dialect is perceived as the dialect of the people from the rural areas of Thailand. But Isan people are forced to speak more neutral Thai in their daily life to avoid being perceived as bring from the countryside. This is how language can be eliminated through time.

Moreover, local culture can be replaced by the new culture when people seem to practice the new culture more. Original Thai parades during the wedding are disappearing while having champagne toast during the ceremony is getting more popular. When Thai DJs talked about New Year they meant 1 January, but in fact Thai New Year is in April. Thais can also adopt new perspectives and attitudes to life. The perspective on consuming alcohol has changed since the times when the consumption of alcohol consumption was perceived as sin (from Thai Buddhism perspective). Today an alcoholic drink can be a symbol of successful life.

Languages and cultures are changing continuously and the media are one of the causes of this change. It is impossible to totally stop embracing the new cultures as well as totally leave the old cultures. These changes in language and cultures take time and it is important for both the audiences and the media producers to be aware of such changes.

\section{REFERENCES}

Bakhtin, M. (1986). Speech Genres and Other Late Essays. Moscow: University of Texas Press.

Conlon, S. (2012). Ecology of the Language and the Novel. Retrieved from Assumption Journal: http://www.assumptionjournal.au.edu/index.php/AsianJournal/article/view/34 $5 / 300$

Fairclough, N. (1989). Language and Power. New York: Longman.

Fairclough, N. (1995). Critical Discourse Analysis. New York: Addison Wesley Longman.

Fairclough, N. (2005). Critical discourse analysis in transdisciplinary research. Dalam Wodak, R. and Chilton, P. 2005. A New Agenda in (Critical) Discourse Analysis. Amsterdam: John Benjamnis Publishing. Hal 53-70

Fauzan, Umar. (2013). Ideology of the News Text of tvOne: A Study of Critical Discourse Analysis. Proceedings of $1^{\text {st }}$ Educational Linguistics Conference. May, 2013. pp. 500-508. UNY Yogyakarta.

Foley, J. A. (2013). Sociology of Language. Bangkok, Thailand: Assumption University Press.

Gumperz, J. J. (1982). Language and Social Identity. Melbourne: Cambridge University Press.

Khansuwan, S. (1996). Introduction to Journalism. Bangkok: Prakaipruek Press.

Martin, J., \& Macken, M. (2002). Introduction: The Origin of the Appraisal Framework. Retrieved from grammatics: http://www.grammatics.com/appraisal/AppraisalGuide/UnFramed/AppraisalOverview.htm 
A CDA of of Thai and American Music Radio Programs

\begin{tabular}{|c|c|c|}
\hline MCOT & Company's & Business, \\
\hline
\end{tabular}

